\title{
CAUSALITY AND CONTAGION IN EMU SOVEREIGN DEBT MARKETS $^{*}$
}

\author{
Marta Gómez-Puig ${ }^{a}$ \\ (Universitat de Barcelona and RFA-IREA, Spain) \\ Simón Sosvilla-Rivero ${ }^{\mathrm{b}}$ \\ (Universidad Complutense de Madrid, Spain) \\ Revised version \\ February 2014
}

\begin{abstract}
This paper contributes to the literature by applying the Granger-causality approach and endogenous breakpoint test to offer an operational definition of contagion to examine European Economic and Monetary Union (EMU) countries public debt behaviour. A database of yields on 10-year government bonds issued by 11 EMU countries covering fourteen years of monetary union is used. The main results suggest that the 41 new causality patterns, which appeared for the first time in the crisis period, and the intensification of causality recorded in $70 \%$ of the cases, provide clear evidence of contagion in the aftermath of the current euro debt crisis.
\end{abstract}

Keywords: Sovereign bond yields, Granger-Causality, Contagion, Euro area.

JEL Classification: E44, F36, G15, C52

\footnotetext{
* a Department of Economic Theory, Universitat de Barcelona, Av. Diagonal 696, 08034 Barcelona, Spain. E-mail: marta.gomezpuig@ub.edu. b Department of Quantitative Economics, Universidad Complutense de Madrid, Campus de Somosaguas, 28223 Madrid, Spain. E-mail: sosvilla@,ccee.ucm.es. Corresponding author: Simón Sosvilla-Rivero, Department of Quantitative Economics, Universidad Complutense de Madrid, 28223 Madrid, Spain. T: 34-913 942342. Fax: 34- 913942591.
} 


\section{Introduction}

From the introduction of the euro in January 1999 until the collapse of the US financial institution Lehman Brothers in September 2008, sovereign yields of euro area issues moved in a narrow range with only very slight differences across countries (see Figures 1 and 2). Nevertheless, following the Lehman Brothers collapse severe tensions emerged in financial markets worldwide, including the euro zone bond market. In fact, not only did the period of financial turmoil turn into a global financial crisis, but it also began to spread to the real sector, with a rapid, synchronized deterioration in most major economies. This financial crisis put the spotlight on the macroeconomic and fiscal imbalances within European Economic and Monetary Union (EMU) countries which had largely been ignored during the period of stability when markets had seemed to underestimate the possibility that governments might default (see Beirne and Fratzscher, 2013). Furthermore, in some EMU countries, problems in the banking sector spread to sovereign states because of their excessive debt issues made in order to save the financial industry; eventually, the global financial crisis grew into a full-blown sovereign debt crisis. Indeed, since 2010, Greece has been bailed out twice and Ireland, Portugal and Cyprus have also needed bailouts to stay afloat. These events brought to light the fact that the origin of sovereign debt crises in the euro area varies according to the country and reflects the strong interconnection between public and private debt (see Gómez-Puig and Sosvilla-Rivero, 2013) ${ }^{1}$.

In this scenario, some of the research to date has focused on the analysis of interactions between the sovereign market and the financial sector [see Mody (2009), Ejsing and Lemke (2009), Gennaioli et al. (2013), Broner et al. (2011), Bolton and Jeanne (2011) and Andenmatten and Brill (2011)]. Other researchers have discussed transmission and/or contagion between sovereigns in the euro area context [see Kalbaska and Gatkowski

\footnotetext{
${ }^{1}$ Moro (2013) and Aizenman (2013) offer a literature review on the Eurozone economic and financial crisis.
} 
(2012), Metiu (2012), Caporin et al. (2013), Beirne and Fratzscher (2013) and Gorea and Radev (2014) to name a few]. Finally, a strand of research has examined structural breaks and sovereign credit risk in the Eurozone [see, e. g., Basse et al. (2012), Gruppe and Lange (2013) and Basse (2013)].

The aim of this paper is to contribute to the last two branches of the literature by examining not only the transmission of sovereign risk, but also the contagion in euro area public debt markets. In the literature there is a considerable amount of ambiguity concerning the precise definition of contagion. There is no theoretical or empirical definition on which researchers agree and, consequently, the debate on exactly how to define contagion is not just academic, but also has important implications for measuring the concept and for evaluating policy responses. Pericoli and Sbracia (2003) note five definitions of contagion used in the literature. Two of them have been predominantly used in empirical studies to analyze it in financial markets and have been adopted in common usage by governments, citizens and policymakers. The first defines contagion depending on the channels of transmission that are used to spread the effects of the crisis, whilst the second defines it depending on whether the transmission mechanisms are stable through time.

Masson (1999) and Kaminsky and Reinhart (2000) apply the first definition, which argues that contagion arises when common shocks and all channels of potential interconnection are either not present or have been controlled for. So, the term contagion will only be applied when a crisis in one country may conceivably trigger a crisis elsewhere for reasons unexplained by macroeconomic fundamentals ${ }^{2}$ - perhaps because it leads to shifts in

\footnotetext{
2 The theory of "monsoonal effects" suggests that financial crises appear to be contagious because underlying macroeconomic variables are correlated. In this context, several important papers have focused on the macroeconomic causes of crises, for example, Eichengreen et al. (1996).
} 
market sentiment, or changes the interpretation given to existing information. According to the second definition, which was proposed in a seminal paper by Forbes and Rigobon (2002), contagion is a significant increase in cross-market linkages after a shock to one country (or group of countries) ${ }^{3}$. Therefore, if two markets show a high degree of comovement during periods of stability, even if they continue to be highly correlated after a shock to one market, this may not constitute contagion, but only the outcome of the "interdependence" that has always been present in the markets. The empirical analysis of Forbes and Rigobon definition of contagion implies then the presence of a tranquil, precrisis period in order to be able to examine whether a change in the intensity of the transmission has occurred after the shock.

In this paper, we will use an operational approach based on the second of these definitions ${ }^{4}$ in order to capture the phenomenon of contagion quantitatively. Besides, among the five general strategies ${ }^{5}$ that have been used in the literature, our analysis will be related to one of the most conventional methodologies for testing for contagion: the analysis of crossmarket correlations. However, we not only investigate changes in cross-market interdependencies via cointegration analysis, but also explore changes in the existence and direction of causality by means of a Granger-causality approach ${ }^{6}$ before and after endogenously (data-based) identified crises. Hence, the definition of contagion that we will explore in the remainder of this paper is the following: an abnormal increase in the number

\footnotetext{
3 The distinction between contagion which occurs at times of crisis, and interdependence which is a result of normal market interaction, has become the focal point of many contagion studies: see for example Corsetti et al. (2005) or Bae et al. (2003).

${ }^{4}$ In a very recent paper, Gómez-Puig and Sosvilla-Rivero (2014), analyze contagion using an approach that is based in the first definition of contagion [(Masson, 1999) and Kaminsky and Reinhart (2000) among others]. Concretely, they examine whether the transmission of the recent crisis in euro area sovereign debt markets was due to fundamentals-based or pure contagion. Their results suggest the importance of both variables proxying market sentiment and macrofundamentals in determining contagion and underline the coexistence of "pure contagion" and "fundamentals-based contagion" during the recent European debt crisis.

5 Probability analysis, cross-market correlations, VAR models, latent factor/GARCH models, and extreme value/coexceedance/jump approach (see Forbes, 2012).

${ }^{6}$ Forbes and Rigobon (2002) suggest the use of this methodology when they point out that, if the source of the crisis is not well identified and endogeneity may be severe, it may be useful to utilize Granger-causality tests to determine the extent of any feedback from each country in the sample to the initial crisis country.
} 
or in the intensity of causal relationships, compared with that of tranquil periods, triggered after an endogenously detected shock.

Most studies in the literature investigate changes in cross-market correlations (see, e. g., Syllignakis and Kouretas, 2011); very few explore changes in the existence and direction of causality. Exceptions are studies by Edwards (2000) who focuses on Chile, Baig and Goldfajn (2001) who investigate contagion from Russia to Brazil, Gray (2009) who examines spillovers in Central and Eastern European countries, and both Granger et al. (2000) and Sander et al. (2003) who investigate spillovers during the Asian crisis. However, a small number of studies have applied a Granger-causality approach to the investigation of changes in the existence and direction of transmission in euro area debt markets. Among them, Kalbaska and Gatkowski (2012) analyze the dynamics of the credit default swap (CDS) market of peripheral EMU countries along with three central European countries (France, Germany and the UK) for the period of 2008-2010, and Gómez-Puig and Sosvilla-Rivero (2013) focus on the existence of possible Granger-causal relationships between the evolution of the yield of bonds issued solely by peripheral EMU countries during the period 1999-2010.

Therefore, our study contributes to this literature by applying a Granger-causality approach to 10 -year sovereign yields ${ }^{7}$ of both peripheral and central EMU countries $^{8}$ on an extended time period spanning from the inception of the euro in January 1999, well before the global financial and sovereign debt crises, until December 2012. But, unlike previous studies in the literature (see Sander et al., 2003 o Kalbaska and Gatkowski, 2012), we do not set a

\footnotetext{
7 Our analysis focuses on 10-year yields instead of CDS since CDS data are not available for all the countries in the study until late 2008 - only one year before the onset of the euro sovereign debt crisis.

${ }^{8}$ Gómez-Puig and Sosvilla-Rivero (2013) report data of consolidated claims on an immediate borrower basis provided by the Bank for International Settlements by nationality of reporting banks as a proportion of total foreign claims on each country. These data suggest that the problems of peripheral countries can trigger contagion which may affect not only other peripheral countries but also central EMU countries, since some of these banks (mostly German and French banks) are highly exposed to the debt of peripheral countries.
} 
specific breakpoint based on a priori knowledge of the potential break date. In our analysis, we use two techniques that take into consideration that the timing of the break is unknown and allow the data to indicate when regime shifts occur. Thus, break dates that identify the shock triggering contagion are determined endogenously by the model in each of the potential pair-wise causal relationships ${ }^{9}$.

The rest of the paper is organized as follows. The next section explains the econometric methodology. The dataset used to analyze causality is described in Section 3. Section 4 presents the empirical findings, whilst Section 5 offers some concluding remarks.

\section{Econometric methodology}

\subsection{Testing for causality}

Granger's (1969) causality test is widely used to test for the relationship between two variables. A variable $X$ is said to Granger-cause another variable $Y$ if past values of $X$ help predict the current level of $Y$ better than past values of $Y$ alone, indicating that past values of $X$ have some informational content that is not present in past values of $Y$. This definition is based on the concept of causal ordering: two variables $X$ and $Y$ may be contemporaneously correlated by chance, but it is unlikely that the past values of $X$ will be useful in predicting $Y$, giving all past values of $Y^{10}$.

\footnotetext{
${ }^{9}$ In the analysis we only analyze shock transmission between pairs, considering in each test that only one country is responsible of spreading the shock. Unlike previous crisis, since in the euro area sovereign debt crisis several peripheral countries entered a fiscal crisis at roughly the same time, it is very difficult to identify the country responsible of the origin of the shock.

${ }^{10}$ Granger causality is not identical to causation in the classical philosophical sense, but it demonstrates the likelihood of this causation more forcefully than contemporaneous correlation (Geweke, 1984).
} 
Granger-causality tests are sensitive to lag length and, therefore, it is important to select the appropriate lengths ${ }^{11}$. Otherwise, the model estimates will be inconsistent and the inferences drawn may be misleading (see Thornton and Batten, 1985). In this paper, we use Hsiao's (1981) generalization of the Granger notion of causality. Hsiao proposed a sequential method to test for causality, which combines Akaike (1974)'s final predictive error (FPE, from now on) and the definition of Granger-causality (Canova 1995, 62-63). Essentially, the FPE criterion trades off the bias that arises from underparameterization of a model against the loss in efficiency that results from its overparameterization.

Consider the following models,

$$
\begin{gathered}
Y_{\mathrm{t}}=\alpha_{0}+\sum_{i=1}^{M} \delta_{i} Y_{t-i}+\varepsilon_{t} \\
Y_{t}=\alpha_{0}+\sum_{i=1}^{M} \delta_{i} Y_{t-i}+\sum_{j=1}^{N} \gamma_{j} X_{t-j}+\varepsilon_{t}
\end{gathered}
$$

where $X_{t}$ and $Y_{t}$ are covariance-stationary variables [i.e., they are $\mathrm{I}(0)$ variables]. The following steps are used to apply Hsiao's procedure for testing causality:

i) Treat $Y_{t}$ as a one-dimensional autoregressive process (1), and compute its FPE with the order of lags $m_{i}$ varying from 1 to $M$. Examine the FPE

$$
\operatorname{FPE}_{Y}\left(m_{i}, 0\right)=\frac{T+m_{i}+1}{T-m_{i}-1} \cdot \frac{S S R}{T}
$$

where $T$ is the total number of observations and SSR is the sum of squared residuals of OLS regression (1). Choose $m_{i}$ for the value of $m$ that minimizes the FPE, say $m$, and denote the corresponding value as $\operatorname{FPE}_{\mathrm{Y}}(\mathrm{m}, 0)$.

ii) Treat $Y_{t}$ as a controlled variable with $m$ number of lags, and treat $X_{t}$ as a manipulated variable as in (2). Compute again the FPE of (2) by varying the order of lags $n_{i}$ of $X_{t}$ from 1 to $N$. Examine the FPE

11 The general principle is that the smaller lag length has smaller variance but runs a risk of bias, while larger lags will reduce the bias problem but may lead to inefficiency. 
$F P E_{Y}\left(m_{i}, n_{i}\right)=\frac{T+m_{i}+n_{i}+1}{T-m_{i}-n_{i}-1} \cdot \frac{S S R}{T}$

Choose the order $n_{i}$ which gives the smallest FPE, say $n$, and denote the corresponding FPE as $\mathrm{FPE}_{\mathrm{Y}}(\mathrm{m}, \mathrm{n})$.

iii) $\quad$ Compare $\operatorname{FPE}_{\mathrm{Y}}(\mathrm{m}, 0)$ with $\operatorname{FPE}_{\mathrm{Y}}(\mathrm{m}, \mathrm{n})$ [i.e., compare the smallest FPE in step (i) with the smallest FPE in step (ii)]. If $\operatorname{FPE}_{\mathrm{Y}}(\mathrm{m}, 0)-\mathrm{FPE}_{\mathrm{Y}}(\mathrm{m}, \mathrm{n})>0$, then $X_{t}$ is said to cause $Y_{t}$. If $\mathrm{FPE}_{\mathrm{Y}}(\mathrm{m}, 0)-\mathrm{FPE}_{\mathrm{Y}}(\mathrm{m}, \mathrm{n})<0$, then $Y_{t}$ is an independent process.

iv) Repeat steps i) to iii) for the $X_{t}$ variable, treating $Y_{t}$ as the manipulated variable.

When $X_{t}$ and $Y_{t}$ are not stationary variables, but are first-difference stationary [i.e., they are I(1) variables] and cointegrated (see Dolado et al., 1990), it is possible to investigate the causal relationships from $\Delta X_{t}$ to $\Delta Y_{t}$ and from $\Delta Y_{t}$ to $\Delta X_{t}$, using the following error correction models:

$$
\begin{aligned}
& \Delta Y_{t}=\alpha_{0}+\beta Z_{t-1}+\sum_{i=1}^{M} \delta_{i} \Delta Y_{t-i}+\varepsilon_{t} \\
& \Delta Y_{t}=\alpha_{0}+\beta Z_{t-1}+\sum_{i=1}^{M} \delta_{i} \Delta Y_{t-i}+\sum_{j=1}^{N} \gamma_{j} \Delta X_{t-j}+\varepsilon_{t}
\end{aligned}
$$

where $Z_{t}$ is the OLS residual of the cointegrating regression $\left(Y_{t}=\mu+\lambda X_{t}\right)$, known as the error-correction term. Note that, if $X_{t}$ and $Y_{t}$ are $\mathrm{I}(1)$ variables but are not cointegrated, then $\beta$ in (3) and (4) is assumed to be equal to zero.

In both cases [i.e., $X_{t}$ and $Y_{t}$ are $\mathrm{I}(1)$ variables, and they are or they are not cointegrated], we can use Hsiao's sequential procedure substituting $Y_{t}$ with $\Delta Y_{t}$ and $X_{t}$ with $\Delta X_{t}$ in steps (i) to (iv), as well as substituting expressions (1) and (2) with equations (3) and (4). 


\subsection{Stability Diagnostics}

In the conventional Granger-causality analysis, the relationship between two variables is assumed to exist at all times. However, in a context of financial crisis, parameter nonconstancy may occur and may generate misleading inferences if left undetected (see, Bai and Perron, 1998, 2003; Perron, 1989; Zivot and Andrews, 1992). Furthermore, the pretesting issue in early studies may induce a size distortion of the resulting test procedures (Bai, 1997). Thus, it is desirable to let the data select when and where regime shifts occur (i. e., we need to test for the null hypothesis of no structural change versus the alternative hypothesis that changes are present). To this end, we first identify a single structural change using the Quandt-Andrews one-time unknown structural break test. We then use the procedure suggested by Bai (1997) and Bai and Perron (1998, 2003) to detect multiple unknown breakpoints in order to obtain further evidence of the existence of the breakpoints previously detected endogenously. These breakpoints allow the identification of pre-crisis and crisis periods for each pair-wise causal relationship which, as explained in the Introduction, are needed for the detection of a possible contagion episode according to our operational definition based on Forbes and Rigobon (2002) approach.

\subsubsection{Quandt-Andrews Breakpoint Test}

A particular challenge in empirical time series analysis is to determine the appropriate timing of a potential structural break. In a traditional Chow (1960) test ${ }^{12}$, we have to set a specific breakpoint based on a priori knowledge about the potential break date. In our analysis, however, we do not assume any prior knowledge about potential break dates, but we make use of a data-based procedure to determine the most likely location of a break. In particular, we use the Quandt-Andrews unknown breakpoint test, originally introduced by

\footnotetext{
12 The basic idea of the breakpoint Chow test is to fit the equation separately for each subsample and to see whether there are significant differences in the estimated equations. A significant difference indicates a structural change in the relationship.
} 
Quandt (1960) and later developed by Andrews (1993) and Andrews and Ploberger (1994). The idea behind the Quandt-Andrews test is that a single Chow breakpoint test is performed at every observation between two dates, or observations $\left(\tau_{1}\right.$ and $\left.\tau_{2}\right)$. The $k$ test statistics from those Chow tests are then summarized into one test statistic for a test against the null hypothesis of no breakpoints between $\tau_{1}$ and $\tau_{2}$.

For the unknown break date, Quandt (1960) proposed likelihood ratio test statistics for an unknown change point, called Supremum test, while Andrews (1993) supplied analogous Wald and Lagrange Multiplier test statistics for it. Then Andrews and Ploberger (1994) developed Exponential (LR, Wald and LM) and Average (LR, Wald and LM) tests. These tests are calculated by using individual Chow Statistics for each date of the data except for some trimmed portion from both ends of it. While the Supremum test finds the date that maximizes Chow Statistics, the most possible break point, the Average and Exponential tests use all the Chow statistic values and are only informative about the existence of the break but not about its date ${ }^{13}$.

We set a search interval $\tau \in[0.15,0.85]$ for the full sample $T$ to allow a minimum of $15 \%$ of effective observations contained in both pre- and post-break periods. These tests allow us to determine a structural change with unknown timing endogenously from the data after examining each date of the data except for some trimmed portion from both ends of it.

\subsubsection{Multiple Breakpoint Tests}

Bai and Perron (1998) develop tests for multiple structural changes. Their methodology can be disentangled in two separate and independent parts. First, they propose a sequential method to identify any number of breaks in a time series, regardless of their statistical

13 Andrews (1993) and Andrews and Ploberger (1994) provide tables of critical values, and Hansen (1997) provides a method to calculate $p$-values. 
significance. Second, once the breaks have been identified, they propose a series of statistics to test for the statistical significance of these breaks, using asymptotic critical values.

The sequential procedure is as follows:

i. Begin with the full sample and perform a test of parameter constancy with unknown break.

ii. If the test rejects the null hypothesis of constancy, determine the breakdate, divide the sample into two samples and perform single unknown breakpoint tests in each subsample. Add a breakpoint whenever in a subsample null is rejected.

iii. Repeat the procedure until all of the subsamples do not reject the null hypothesis, or until the maximum number of breakpoints allowed or maximum subsample intervals to test is reached.

For a specific set of unknown breakpoints $\left(T_{1}, \ldots, T_{p}\right)$, we use the following set of tests developed by Bai and Perron $(1998,2003)$ to detect multiple structural breaks: the sup F type test, the double maximum tests, and the test for $\ell$ versus $\ell+1$ breaks. First, we consider the sup $F$ type test of no structural breaks $(p=0)$ versus the alternative hypothesis that there are $p=k$ breaks. Second, we use the double maximum tests, UDmax and WDmax, testing the null hypothesis of no structural breaks against an unknown number of breaks given some upper bound $m^{*}$. Finally, the sup $F_{T}(\ell+1 / \ell)$ test, which is a sequential test of the null hypothesis of $\ell$ breaks against the alternative of $\ell+1$ breaks. The test is applied to each segment containing the observations $\hat{T}_{i-1}$ to $\hat{T}_{i}$ $i=1, \ldots,(\ell+1)$. To run these tests it is necessary to decide the minimum distance between two consecutive breaks, $h$, which is obtained as the integer part of a trimming parameter, 
$\varepsilon$, multiplied by the number of observations $T$ (we use $\varepsilon=0.15$ and allow up to four breaks).

\subsection{Testing for Causality Intensification}

As stated above, Granger causality measures precedence and information content. Therefore, the statement " $X$ Granger causes $Y$ " implies that past values of $X$ provide relevant and valuable information about the future behaviour of $Y$ that is not present in past values of $Y$.

Since the statistic we use to detect Granger-causality is $\operatorname{FPE}_{\mathrm{Y}}(\mathrm{m}, 0)-\mathrm{FPE}_{\mathrm{Y}}(\mathrm{m}, \mathrm{n})$, we can compute this statistic before and after the endogenously identified breakpoint, and thus assess the intensification or reduction in the causal relationship for those pairs in which we have found Granger-causality in both periods. Therefore, we take an increase of Granger causality as an amplification of the statistical predictability of one time series for another as evidence of an intensification in the transmission mechanism between them.

To this end, for each pair-wise relationship where we find causality both in the tranquil and in the crisis periods, we compare $\operatorname{FPE}_{\mathrm{Y}}(\mathrm{m}, 0)-\mathrm{FPE}_{\mathrm{Y}}(\mathrm{m}, \mathrm{n})$ in these periods. If this statistic is higher in the crisis than in the tranquil period, we can conclude that an intensification in the causal relationship has taken place. Indeed, this result shows that in the crisis period, even though the uncertainty is by definition higher, the $X_{t}$ (or $\Delta X_{t}$ ) in equation (2) [or in equation (4)] contains relatively more useful information for forecasting the $Y_{t}$ (or $\Delta Y_{t}$ ) which is not contained in past values of $Y_{t}$ (or $\Delta Y_{t}$ ), than during the pre-crisis period. Conversely, if this statistic is lower in the crisis period than in the tranquil one, we can infer a reduction in the causal relationship, since the extra lagged variables are less useful now 
for providing information about the future behaviour of the yield under study during the crisis period than during the pre-crisis period.

In doing so, we are first evaluating the "forecast conditional efficiency" in the terminology of Granger and Newbold $(1973,1986)$ [or "forecast encompassing" according to Chong and Hendry (1986) and Clements and Hendry (1993)] of the manipulated variable $X_{t}$ (or $\Delta X_{t}$ ) in equation (2) [or equation (4)] for each period, by examining whether $X_{t}\left(\right.$ or $\left.\Delta X_{t}\right)$ contains useful information for forecasting the $Y_{t}$ (or $\Delta Y_{t}$ ) which is not contained in past values of $Y_{t}$ (or $\Delta Y_{t}$ ), and then comparing them and assessing the relative gains in forecast accuracy in each period.

\section{Data}

We use daily data of 10 -year bond yields from January $1^{\text {st }} 1999$ to December $31^{\text {st }} 2012$ collected from Thomson Reuters Datastream for EMU-11 countries: both central (Austria, Belgium, Finland, France, Germany and the Netherlands) and peripheral countries (Greece, Ireland, Italy, Portugal and Spain).

[Insert Figure 1 and Figure 2 here]

Figure 1 plots the evolution of daily 10-year bond yields for each country in our sample, whilst Figure 2 displays the evolution of their spread against the German bund. A simple look at these figures allows us to identify two periods, although the breakpoint is not the same in all countries. Between January 1999 and summer 2008, the 10-year bond yields of different countries were evolving simultaneously, and spreads presented only small differences across countries. Only at the end of this period, following the collapse of Lehman Brothers in September 2008, did the major tensions emerging in the financial markets worldwide affect the euro area sovereign debt market since, in a context in which 
the crisis had already reached the real sector, the problems in the banking sector began to spread to euro area sovereign states.

The descriptive statistics of the 10-year government bond yields in EMU countries during the sample period, (not reported here to save space, but available from the authors upon request) suggest that the mean is not significantly different from zero for the first differences and that normality is strongly rejected for both the levels and first differences. Our results also indicate the presence of heteroskedaticity, in line with the findings by Favero and Missale (2012) and Groba et al. (2013) among many others.

\section{Empirical results}

\subsection{Preliminary analysis}

As a first step, we tested for the order of integration of the 10-year bond yields by means of the Augmented Dickey-Fuller (ADF) tests. Then, following Cheung and Chinn (1997)'s suggestion, we confirm the results using the Kwiatkowski et al. (1992) (KPSS) tests, where the null is a stationary process against the alternative of a unit root. The results, not shown here to save space but available from the authors upon request, decisively reject the null hypothesis of non-stationarity in the first regressions. They do not reject the null hypothesis of stationarity in first differences, but strongly reject it in levels, in the second ones. So, they suggest that both variables can be treated as first-difference stationary.

As a second step, we tested for cointegration between each of the 55 pair combinations ${ }^{14}$ of EMU-11 yields using Johansen $(1991,1995)$ 's approach. The results suggest ${ }^{15}$ that only

\footnotetext{
${ }^{14}$ Recall that the number of possible pairs between our sample of EMU-11 yields is given by the following formula $\frac{n !}{r !(n-r) !}=\frac{11 !}{2 !(11-2) !}=55$

${ }^{15}$ The results are not presented, either, to save space but are available from the authors upon request.
} 
for the Austria-Finland, Austria-France, Finland-France, Finland-Netherlands, GreeceIreland, Greece-Portugal, Ireland-Italy, Ireland-Portugal, Italy-Netherlands and ItalyPortugal cases does the trace test indicate the existence of one cointegrating equation at least at the 0.05 level. Therefore, for these pairs we test for Granger-causality in the first difference of the variables, with an error-correction term added [i. e., equations (3) and (4)], whereas for the remaining cases, we test for Granger-causality in the first difference of the variables, with no error-correction term added [i. e., equations (3) and (4) with $\beta=0$ ]

\section{2. Detecting structural breakpoints}

As we explained above, in order to detect contagion in the euro area sovereign debt markets, we need to identify a tranquil or pre-crisis period. To do so, unlike previous studies, we do not set a specific breakpoint based on a priori knowledge about the potential break date; first we apply the Quandt-Andrews breakpoint test and let the data select when regime shifts occur in each potential causal relationship, and later we confirm the identified breakpoint by using the tests developed by Bai and Perron $(1998,2003)$ to detect multiple structural breaks ${ }^{16}$. Table 1 shows that $70 \%$ of the total break dates (77 out of the 110 cases analysed) can be explained by some of the following five triggering events ${ }^{17}$ : (1) the increase in the ECB interest rates by 25 basis points on July $3^{\text {rd }} 2008$; (2) the Lehman Brothers collapse on September $15^{\text {th }}$ 2008; (3) the admission by Papandreou's government that its finances were far worse than in previous announcements in November 2009; (4) Greece's request for financial support on April 23 $3^{\text {rd }} 2010$; and (5) Ireland's request of financial support on November $21^{\text {st }} 2010$.

[Insert Table 1 here]

\footnotetext{
${ }_{16}$ We compute the breakpoint tests using a statistic which is robust to heteroskedasticity, since we estimate our original equations with Newey and West (1987) standard errors.

17 In order to save space, the numerical results of Quandt-Andrews and Bai-Perron tests are not reported in Table 1, but they are also available upon request.
} 
These results suggest that not only can most of the breakpoints be explained by systemic shocks, but that more than half of them (60 out of 110$)$ are directly connected to the euro sovereign debt crisis (triggering events 4 to 5). Besides, 69 out of the 110 breakpoints (i. e., 63\%) occur after November 2009, after Papandreou's government had disclosed that its finances were far worse than previously announced ${ }^{18}$, with a yearly deficit of $12.7 \%$ of GDP, four times more than the euro area's limit (and more than double the previously published figure), and a public debt of $\$ 410$ billion. We should recall that this announcement only served to worsen the severe crisis in the Greek economy, and the country's debt rating was lowered to $\mathrm{BBB}+$ (the lowest in the euro zone) on December $8^{\text {th }}$. These episodes marked the beginning of the euro area sovereign debt crisis.

Furthermore, it is also notable that all break dates, including the $30 \%$ which are not related to one of the five triggering events mentioned above ${ }^{19}$, occur between January 2008 and December 2010, suggesting that systemic rather than idiosyncratic factors explain euro area sovereign debt market turmoil. Therefore, since the precise regime shift date changes depending on the causal relationship, our analysis improves on previous studies by using in each relationship the breakpoint obtained from the Quandt-Andrews and Bai-Perron tests.

\section{3. Changes in the number of Granger-causal relationships}

Given the evidence presented in the previous sub-section, in ten relationships (AustriaFinland, Austria-France, Finland-France, Finland-Netherlands, Greece-Ireland, GreecePortugal, Ireland-Italy, Ireland-Portugal, Italy-Netherlands and Italy-Portugal) we test for Granger-causality in the first difference of the variables, with an error-correction term

\footnotetext{
18 These results are in line with Gómez-Puig and Sosvilla-Rivero (2014) who find that none of the variables measuring global (world) market sentiment was statistically significant, suggesting that shifts in local (country-specific) or regional (European) rather than global market sentiment are behind euro area debt crisis transmission.

${ }_{19}$ We make use of equality tests to formally evaluate the null hypothesis that the mean and variance in the pre-crisis and crisis periods are equal against the alternative that they are different. The results (not shown here to save space, but available from the authors upon request) indicate strong evidence that they differ across periods.
} 
added. In all other cases, we test for Granger-causality in the first difference of the variables, with no error-correction term added. The causal relationships resulting from the estimated FPE statistics for the pre-crisis and crisis periods jointly with the break dates resulting from the Quandt-Andrews and Bai-Perron tests are shown in Tables 2 and $3^{20}$.

\section{[Insert Table 2 and Table 3 here]}

The changes in causal relationships in the crisis period compared to the pre-crisis period are illustrated in Figures 3 and 4 (grey arrows represent relationships that did not exist before the breakpoint, whilst discontinuous arrows reflect relationships that disappear with the crisis).

\section{[Insert Figure 3 and Figure 4 here]}

Specifically, Table 2 and Figure 3 present the evolution of the causality running from EMU peripheral countries. The behaviour of causality running from EMU peripheral to central countries is displayed in Panel A of Table 2 and Figure 3a; whilst Panel B of Table 2 and Figure $3 \mathrm{~b}$ show the evolution of causality running within EMU peripheral countries. Likewise, Table 3 and Figure 4 present the changes in causality running from EMU central countries. Panel A of Table 3 and Figure 4a illustrate the evolution of causality running from EMU central to peripheral countries while Panel B of Table 3 and Figure $4 \mathrm{~b}$ report how causality running within EMU central countries has evolved during the two periods.

As can be seen, for the four subsamples of countries, the number of causal relationships increases as the financial and sovereign debt crisis develops in the euro area. If we focus on the evolution of causality between EMU peripheral and EMU central countries (Panels A of Tables 2 and 3 and Figures $3 a$ and 4a), it can be observed that in the pre-crisis period causality is higher if EMU central countries are triggers rather than EMU peripheral

\footnotetext{
20 These results were confirmed using both Wald statistics to test the joint hypothesis $\hat{\gamma}_{1}=\hat{\gamma}_{2}=\ldots=\hat{\gamma}_{n}=0$, and the Williams-Kloot test for forecasting accuracy (Williams, 1959). These additional results are not shown here to save space, but are available from the authors upon request.
} 
countries. In particular, our results indicate the existence of 19 causal relationships in the first case (Figure 4a) and 10 in the second (Figure 3a). Two interesting findings are worth pointing out: (1) in the pre-crisis period, the evolution of Greek sovereign yields does not Granger-cause that of other EMU central countries, and (2) the Netherlands' yield behaviour is not Granger-caused by the evolution of yields of any EMU peripheral country (see Figure 3a).

During the crisis period, even though the number of causal relationships detected increases in both directions, they are more frequent when EMU peripheral countries are the triggers. We find 27 out of 30 causal relationships when the EMU peripheral countries are the triggers (Figure 3a), whilst the number of causality linkages rises from 19 to 24 if the triggers are EMU central countries (Figure 4a). Interestingly, Greece now Granger-causes Austria, Belgium, Finland and France while Netherlands' yield behaviour is caused by the Spanish and the Irish one. Moreover, another relevant finding is that with the crisis, four causal relationships from central to peripheral countries disappear: Austria-Ireland, Belgium-Greece, France-Portugal and Netherlands-Ireland, suggesting a temporal disconnection between them.

Panel B of Table 2 and Figure 3b, which show the results regarding causal relationships running within EMU peripheral countries in the two periods under study, also suggest that their number is boosted as the financial and sovereign debt crises expand in the euro area. We find evidence of 14 relationships in the pre-crisis period (Figure 3b) and 20 in the crisis period. In the pre-crisis period the exceptions are: a) Greece-Ireland, where there is no evidence of Granger-causality in either direction, and b) some relationships where we do not find unidirectional Granger-causality: from Greece to Italy and Spain, and from 
Portugal and Spain to Ireland. Nevertheless, we find evidence of bidirectional causality in all the relationships during the crisis period.

Finally, Panel B of Table 3 and Figure 4b present the results regarding causality running within EMU central countries in the two periods. From these results it can be inferred that the number of causal relationships also increases in the crisis period, since we find evidence of bidirectional causality in all 15 relationships (Figure 4b). Hence, causality linkages increase from 21 to 30 during the crisis compared to the pre-crisis period.

\section{4. Changes in the intensity of Granger-causal relationships}

As mentioned above, for each of the 60 cases where we find causality in both the tranquil and the crisis periods, we compare $\mathrm{FPE}_{\mathrm{X}}(\mathrm{m}, 0)-\mathrm{FPE}_{\mathrm{X}}(\mathrm{m}, \mathrm{n})$ in the two periods. If this statistic is higher in the crisis than in the tranquil period, we can conclude that the causal relationship has intensified. Conversely, if this statistic is lower in the crisis period than in the tranquil one, we can infer a reduction in the causal relationship.

In the last column in Tables 2 and 3, we report the results of this exploratory exercise. As can be seen, even though in the aftermath of the crisis there is an increase in volatility (see Figure 1), we obtain evidence of causality intensification with respect to the more stable pre-crisis period $^{21}$. The causing yields improve the forecast accuracy of the caused yields during the crisis period compared with the tranquil period, indicating that after the detected breakpoint they carry even more useful informational content about the future behaviour of the caused yields.

\footnotetext{
${ }^{21}$ Note that, in contrast to tests for contagion based on cross-market correlation measures, we do not need to adjust for the shift in volatility from the tranquil period to the crisis period.
} 
Regarding the causal relationships running from EMU peripheral to EMU central countries, an increase in causality after the endogenously identified crisis is detected in six of the 10 possible cases (Panel A of Table 2). As for the causality linkages going from EMU central to EMU peripheral countries, in 10 out of the 15 cases where we find causality both in the tranquil and in the crisis period, we find that the relationship intensifies (Panel A of Table 3). With regard to the causal relationships within EMU peripheral countries, we find evidence of significant relative rise in causality after the crisis in 12 out of the 14 possible cases (Panel B of Table 2). Finally, when examining the causal relationships within EMU central countries we conclude that they increase after the crisis in 14 of the 21 possible cases (Panel B of Table 3).

\subsection{Contagion assessment}

From the above analysis we can conclude that, in the crisis period, not only do we find some new causality patterns which had been absent before its start, but also an intensification of causality in $70 \%$ of the cases which would allow us to establish that those linkages may be purely crisis-contingent.

Specifically, causal relationships running from EMU peripheral countries record an important increase in the crisis period: not only relationships within peripheral countries (Figure $3 \mathrm{~b}$ shows six new linkages), but also causal relationships running from EMU peripheral to EMU central countries (Figure 3a displays 17 new causality patterns). This suggests that the problems of peripheral countries can spill over not only to other peripheral countries but also to EMU central countries since some of these banks (mostly German and French banks) are highly exposed to the debt of peripheral countries (see Gómez-Puig and Sosvilla-Rivero, 2013). Moreover, several studies show that sovereign bond yields are not only driven by country-specific risk factors but that they are also 
significantly affected by global risk factors [see Groba et. al. (2013) and Dieckmann and Plank (2011) among them]. These global risk factors reflect global investors' risk aversion, since in times of uncertainty, they become more risk averse and the "flight-to-safety" motive favors bonds of countries that are generally regarded to have a low default risk (e.g. during the crisis Germany experienced one of its lowest yields' levels in history). Therefore, an increase in the Granger-causality of bond yields from peripheral to central countries might also reflect a general increase in investors' risk aversion which might have driven an increase of yields in those countries. Indeed, 10-year yields spreads over Germany of Austrian, Finish, French and Dutch government's bonds achieved a maximum level of 183, 83, 189 and 84 basis points (in November 2011 in the first three countries and in April 2012 in the case of the Netherlands, see Figure 2) while the credit rating provided by the three most important agencies (Moody's, Standard \& Poor's and Fitch) at the same date was, like in Germany, the highest one. The reason behind sovereign risk rise in central countries, triggered by the behaviour of peripheral countries, can be related to herding behavior or panic among investors which leads to what is named by the literature as "pure contagion" (see Gómez-Puig and Sosvilla-Rivero, 2014). Besides, the fact that tensions in sovereign debt markets also spread to EMU central countries is also stressed by the nine new linkages that appear (see Figures $4 \mathrm{a}$ and $4 \mathrm{~b}$ ) both in the causal relationships running from EMU central to EMU peripheral countries and between EMU central countries.

In our view, these 41 new causality patterns out of the 101 causal relationships that exist in the crisis period within the 11 euro area countries analyzed (which were absent before the break date, determined endogenously for each causal relationship), together with the intensification of the causal relationship in 42 of the 60 cases in which we find causality both in the tranquil and in the crisis period, can be considered an important operative measure of contagion consistent with both our definition and the literature, as they 
represent additional linkages during crisis periods in excess of those that arise during noncrisis periods; see for example, Forbes and Rigobon (2002), Masson (1999), Pericoli and Sbracia (2003) or Dungey et al. (2006).

\section{Conclusions}

This paper has three main objectives: to test for the existence of possible Granger-causal relationships between the evolution of the yield of bonds issued by both peripheral and central EMU countries, to determine endogenously the breakpoints in the evolution of those relationships and to detect contagion episodes according to an operative definition: an abnormal increase in the number or in the intensity of causal relationships compared with that of tranquil periods, triggered by an endogenously detected shock.

The most important results that emerge from our analysis are the following: (1) Around two thirds out of the total endogenously identified breakpoints occur after November 2009, when Papandreou's government revealed that its finances were far worse than previous announcements, suggesting that most of the breakpoints can be explained by systemic shocks directly connected to the euro sovereign debt crisis. (2) The number of causal relationships increases as the financial and sovereign debt crisis unfolds in the euro area, and causality patterns after the break dates are more frequent when EMU peripheral countries are the triggers. (3) In the crisis period we find evidence of 101 causal relationships: 41 represent new causality linkages and 60 are patterns that already existed in the tranquil period. However, we find an intensification of the causal relationship in 42 out of the 60 cases. In our opinion, these 41 new causality patterns, together with the intensification of the causal relationship in $70 \%$ of the cases can be considered an important operative measure of contagion that is consistent with the definition we have proposed. 
Regarding policy implications, our results seem to indicate that EMU has brought about strong interlinkages of the participating countries which are reasonable within a group of countries that share an exchange rate agreement (a common currency in the case of the euro area) and where financial crises tend to be clustered (see Beirne and Fratzscher, 2013). Therefore, we consider that our results might have some practical meaning for investors and policymakers, as well as some theoretical insights for academic scholars interested in the behaviour of EMU sovereign debt markets. Our methodology could be used as a tool to provide information regarding the drivers and the time-varying intensity of crisis transmission, in the euro area sovereign debt markets, after a shock, which is an important question that can help policymakers to react in the future in order to avoid another.

Finally, it should be noted that our analysis is devoted to bivariate series analysis. The extension to multivariate series analysis is reserved for future research. In view of the encouraging results of the present study, some optimism about the benefits from implementing this analysis seems justified.

\section{Acknowledgements}

The authors thank the editor and two anonymous referees for useful comments and suggestions on a previous draft of this article, substantially improving the content and quality of the article. This paper is based upon work supported by the Government of Spain and FEDER under grant number ECO2010-21787-C03-01 and ECO2011-23189. Simón Sosvilla-Rivero thanks the Universitat de Barcelona \& RFA-IREA for their hospitality. The authors are very grateful to Petros Migiakis from the Bank of Greece for his comments and suggestions on an early draft. Responsibility for any remaining errors rests with the authors. 


\section{References}

Aizenman J (2013), The eurozone crisis: Muddling through on the way to a more perfect euro union? Social Sciences, 2, 221-23

Andenmatten, S. \& Brill, G. (2011). Measuring co-movements of CDS premia during the Greek debt crisis. Discussion Papers 11-04, Department of Economics, University of Bern.

Andrews, D. W. K. (1993). Tests for parameter instability and structural change with unknown change point. Econometrica, 61, 821-856.

Andrews, D., \& Ploberger, W. (1994). Optimal tests when a nuisance parameter is present only under the alternative. Econometrica, 62, 1383-1414.

Akaike, H. (1974). A new look at the statistical model identification. IEEE Transactions on Automatic Control, 19, 716-723.

Bae, K. H., Karolyi, G. A. \& Stulz, R. M. (2003). A new approach to measuring financial contagion. Review of Financial Studies, 16, 717-763.

Bai, J. (1997). Estimating multiple breaks one at a time. Econometric Theory, 13, 315-352.

Bai, J. \& Perron, P. (1998). Estimating and testing linear models with multiple structural changes. Econometrica, 66, 47-78.

Bai, J. \& Perron, P. (2003). Computation and analysis of multiple structural change models. Journal of Applied Econometrics, 6, 72-78.

Baig, T. \& Goldfajn, I. (2001). The Russian default and the contagion to Brazil. In S. Claessens \& K. Forbes (Eds.), International financial contagion. Boston: Kluwer Academic Publishers.

Banerjee, A., Dolado, J., Galbraith, J. \& Hendry, D. (1993). Cointegration, error correction and the econometric analysis of nonstationary series. Oxford: Oxford University Press.

Basse, T. (2013). Searching for the EMU core member countries, European Journal of Political Economy (in press)

Basse, T., Friedrich, M. \& Kleffner, A. (2012). Italian government debt and sovereign credit risk: an empirical exploration and some thoughts about consequences for European insurers, Zeitschrift für die gesamte Versicherungswissenschaft, 101, 571-579.

Beirne, J. \& Fratzscher, M. (2013). The pricing of sovereign risk and contagion during the European sovereign debt crisis. Journal of International Money and Finance, 34, 60-82.

Bolton, P. \& Jeanne, O. (2011). Sovereign default risk and bank fragility in financially integrated economies. Discussion Paper 8368, Centre for Economic Policy Research.

Broner, F. \& Ventura, J. (2011). Globalization and risk sharing. Review of Economic Studies, 78, 49-82.

Canova, F. (1995). The economics of VAR models. In K. D. Hoover (Ed.) Macroeconometrics: Developments, tensions and prospects, Dordrecht: Kluwer Academic Publishers.

Caporin, M., Pelizzon, L., Ravazzolo, F. \& Rigobon, R. (2013). Measuring sovereign contagion in Europe. Working Paper 18741, National Bureau of Economic Research.

Cheung, Y.-W. \& Chinn, M. D. (1997). Further investigation of the uncertain unit root in GNP. Journal of Business and Economic Statistics, 15, 68-73.

Chong, Y. Y. \& Hendry, D. F. (1990). Econometric evaluation of linear macroeconomic models. Review of Economic Studies, 53, 671-690. 
Chow, G. C. (1960). Tests of equality between sets of coefficients in two linear regressions. Econometrica, 28, 591-605.

Clements, M. P. \& Hendry, D. F. (1993). On the limitations of comparing mean square forecast errors. Journal of Forecasting, 12, 617-637.

Corsetti, G., Pericoli, M. \& Sbracia, M. (2005). 'Some contagion, some interdependence': More pitfalls in tests of financial contagion. Journal of International Money and Finance, 24, 1177-1199.

Dieckmann, S. \& Plank, T. (2012). Default Risk of advanced economies: An empirical analysis of credit default swaps during the financial crisis. Review of Finance, 16, 902-934.

Dolado, J. J., Jenkinson, T. \& Sosvilla-Rivero, S. (1990). Cointegration and unit roots. Journal of Economic Surveys, 4, 149-173.

Dungey, M., Fry, R., González-Hermosillo, B. \& Martin, V. (2006). Contagion in international bond markets during the Russian and the LTCM crises. Journal of Financial Stability, 2, 1-27.

Edwards, S. (2000). Contagion. World Economy, 23, 873-900.

Eichengreen, B., Rose, A. K. \& Wyplosz, C. (1996). Contagious currency crises: First tests. Scandinavian Journal of Economics, 98, 463-484.

Ejsing, J. \& Lemke, W. (2009). The Janus-headed salvation: Sovereign and bank credit risk premia during 2008-09. Working Paper 1127, European Central Bank.

European Central Bank (2012). Global liquidity: Concepts, measurements and implications from a monetary policy perspective. Monthly Bulletin, October, 55-68.

Favero, C. \& Missale, A. (2012). Sovereign spreads in the Euro Area: Which prospects for a Eurobond? Economic Policy, 27, 231-273

Forbes, K. \& Rigobon, R. (2002). No contagion, only interdependence: Measuring stock market comovements. Journal of Finance, 57, 2223-2261.

Forbes, K. (2012). The big C: Identifying contagion. Working Paper 18465, National Bureau of Economic Research.

Gennaioli, N., Martin, A., \& Rossi, S. (2013). Sovereign default, domestic banks and financial institutions. The Journal of Finance, forthcoming.

Geweke, J. (1984). Inference and causality in economic time series models. In Z. Girliches \& M. D. Intriligator (Eds.) Handbook of econometrics. Amsterdam: Elservier Science Publishers.

Gómez-Puig, M. \& Sosvilla-Rivero, S. (2013). Granger causality in peripheral EMU debt markets: A dynamic approach. Journal of Banking and Finance, 37, 4627-4649.

Gómez-Puig, M. \& Sosvilla-Rivero, S. (2014). EMU sovereign debt markets crisis: Fundamental-based or pure contagion? Institut de Recerca en Economia Aplicada (IREA) Working Papers. Universitat de Barcelona. 2014/02.

Gorea, D. \& Radev, D. (2014). The euro area sovereign debt crisis: Can contagion spread from the periphery to the core? International Review of Economics and Finance, 30, 78-100.

Granger, C. W. J. (1969). Investigating causal relations by econometric models and crossspectral methods. Econometrica, 37, 24-36.

Granger, C. W. J. \& Newbold, P. (1973). Some comments on the evaluation of economic forecasts. Applied Economics, 5, 35-47. 
Granger, C. W. J. \& Newbold, P. (1986). Forecasting economic time series. Academic Press, Orlando, FL.

Granger, C.W.J., Huang, W.N. \& Yang, C.W. (2000). A bivariate causality between stock prices and exchange rates: Evidence from the recent Asian flu. The Quarterly Review of Economics and Finance, 40, 337-354.

Gray, D. (2009). Financial contagion among members of the EU-8: A cointegration and Granger causality approach. International Journal of Emerging Markets, 4, 299-314.

Groba, J., Lafuente, J. A. \& Serrano, P. (2013). The impact of distressed economies on the EU sovereign market. Journal of Banking and Finance, 37, 2520-2532.

Gruppe, M. \& Lange, C. (2013). Spain and the European sovereign debt crisis, European Journal of Political Economy (in press).

Hansen, B. E. (1997). Approximate asymptotic $p$ values for structural-change tests. Journal of Business and Economic Statistics, 15, 60-67.

Hsiao, C. (1981). Autoregressive modelling and money-income causality detection. Journal of Monetary Economics, 7, 85-106.

Johansen, S. (1991). Estimation and hypothesis testing of cointegration vectors in gaussian vector autoregressive models. Econometrica, 59, 1551-1580.

Johansen, S. (1994). The role of the constant and linear terms in cointegration analysis of nonstationary variables. Econometric Reviews, 13, 205-229.

Johansen, S. (1995). Likelihood-based inference in cointegrated vector autoregressive models. Oxford: Oxford University Press.

Kalbaska, A. \& Gatkowski, M. (2012). Eurozone sovereign contagion: Evidence from the CDS market (2005-2010). Journal of Economic Behaviour and Organization, 83, 657-673.

Kaminsky, G.L. \& Reinhart, C. M. (2000). On crises, contagion, and confusion. Journal of International Economics, 51, 145-168.

Kwaitkowski, D. Phillips, P.C.B., Schmidt, P. \& Shin, Y. (1992). Testing the null hypothesis of stationarity against the alternative of a unit root: How sure are we that economic time series have a unit root? Journal of Econometrics, 54, 159-178.

MacKinnon, J. G. (1996). Numerical distribution functions for unit root and cointegration tests. Journal of Applied Econometrics, 11, 601-618.

MacKinnon, J. G., Haug, A. A. \& Michelis, L. (1999). Numerical distribution functions of likelihood ratio tests for cointegation. Journal of Applied Econometrics, 14, 563-577.

Masson, P. (1999). Contagion, monsoonal effects, spillovers, and jumps between multiple equilibria. In: P.-R. Agenor, M. Miller, D. Vines \& A. Weber (Eds.), The Asian financial crisis: Causes, contagion and consequences. Cambridge, UK: Cambridge University Press.

Metieu, N. (2012). Sovereign risk contagion in the eurozone. Economics Letters, 117, 35-38.

Mody, A. (2009). From Bear Sterns to Anglo Irish: How Eurozone sovereign spreads related to financial sector vulnerability. Working Paper 09/108, International Monetary Fund.

Moro, B. (2013). Lessons from the European economic and financial great crisis: A survey, European Journal of Political Economy (in press).

Newey, W. K. \& Kenneth D. W. (1987). A simple, positive semi-definite, heteroskedasticity and autocorrelation consistent covariance matrix. Econometrica, 55, 703-708. 
Nielsen, B. \& Rahbek, A. (2000). Similarity issues in cointegration analysis. Oxford Bulletin of Economics and Statistics, 62, 5-22.

Pericoli, M. \& Sbracia, M. (2003). A primer on financial contagion. Journal of Economic Surveys, 17, 571-608.

Perron, P. (1989). The great crash, the oil price shock and the unit root hypothesis. Econometrica, 57, 1361-1401.

Quandt, R. E. (1960). Tests of the hypothesis that a linear regression system obeys two separate regimes. Journal of the American Statistical Association, 55, 324-330.

Sander, H. \& Kleimeier, S. (2003). Contagion and causality: An empirical investigation of four Asian crisis episodes. International Financial Markets, Institutions and Money, 13, 171-186.

Syllignakis, M. N, \& Kouretas, G. P. (2011). Dynamic correlation analysis of financial contagion: Evidence from the Central and Eastern European markets. International Review of Economics and Finance, 20, 717-732

Thornton, D. L. \& Batten, D. S. (1985). Lag-length selection and tests of Granger causality between money and income. Journal of Money, Credit, and Banking, 27, 164-178.

Williams, E. J. (1959). Regression analysis. New York: Wiley.

Zivot, E. \& Andrews, D. W. K. (1992). Further evidence on the great crash, the oil-price shock, and the unit-root hypothesis. Journal of Business and Economic Statistics, 10, 251-270. 
Figure 1. Daily 10-year sovereign yields in EMU-11 countries: 1999-2012

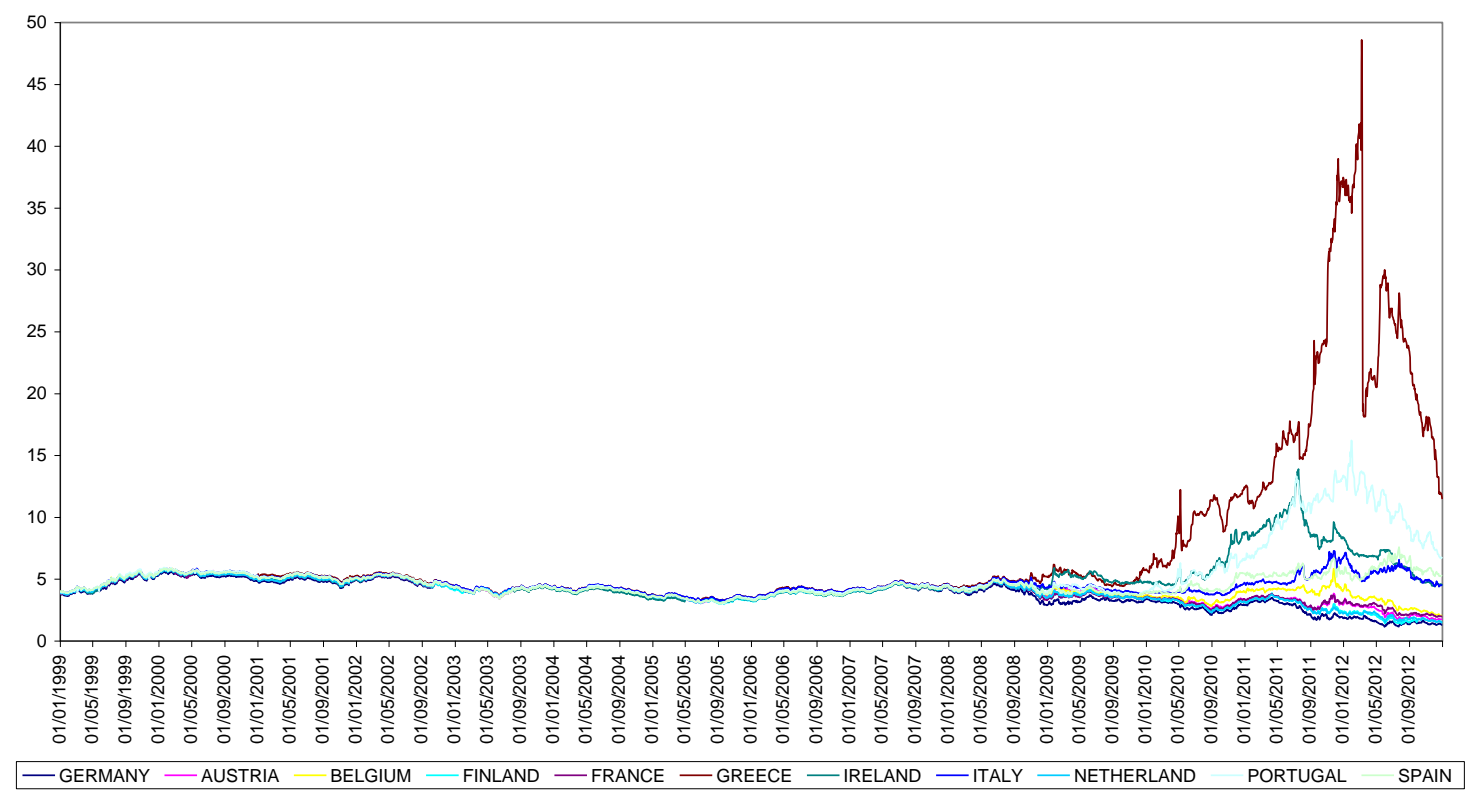

Figure 2. Daily 10-year sovereign yield spreads over Germany: 1999-2012

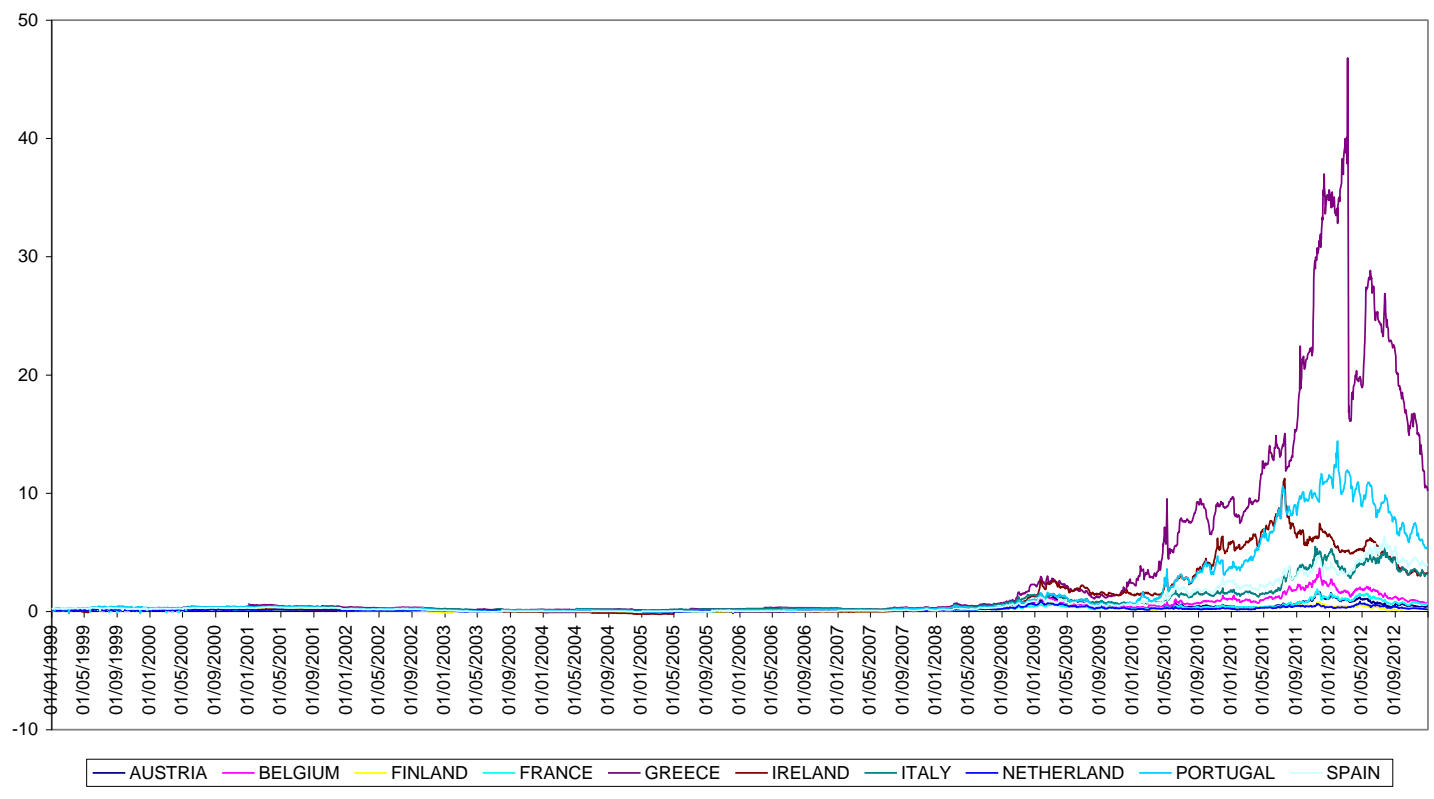


Figure 3: Causal relationships from EMU Peripheral countries.

Figure 3a: Causal relationships from EMU Peripheral to Central countries Pre-crisis Period

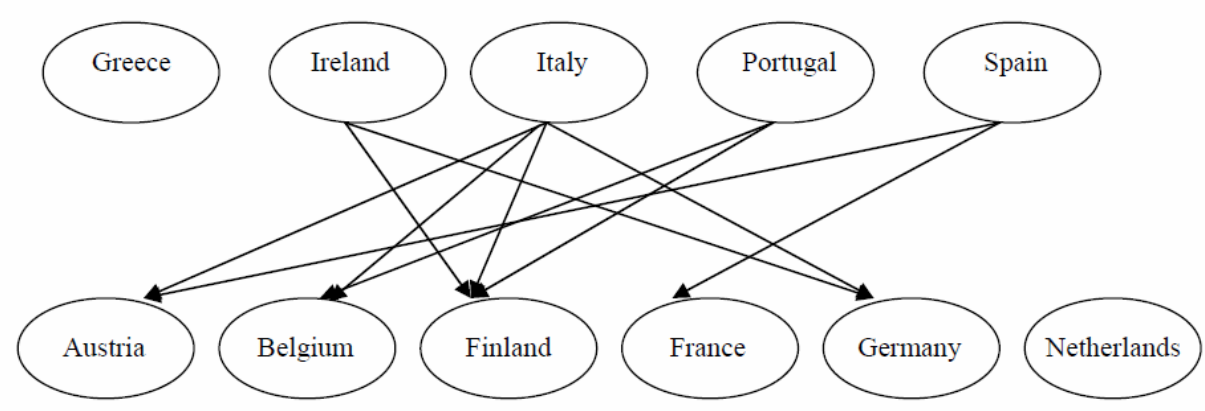

Crisis Period

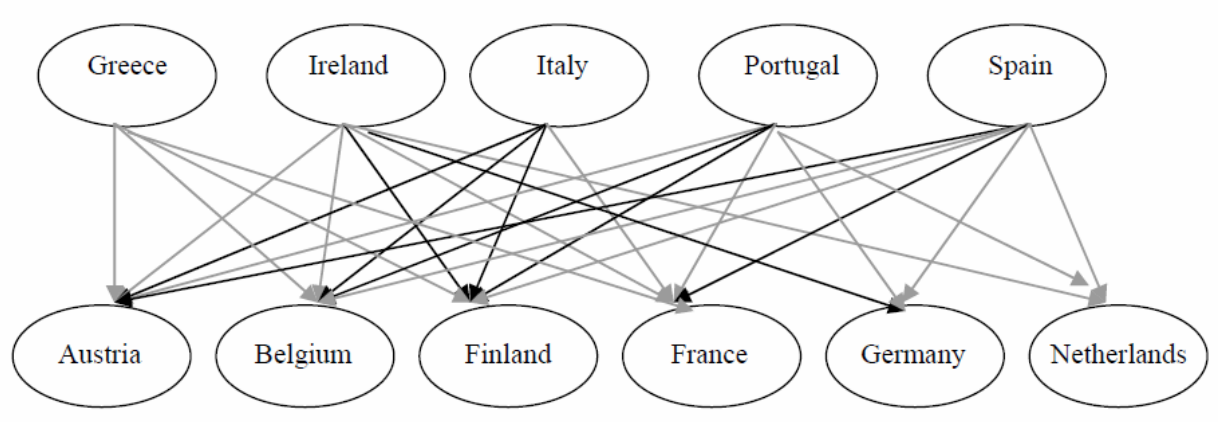

Figure 3b: Causal relationships within EMU Peripheral countries Pre-crisis Period

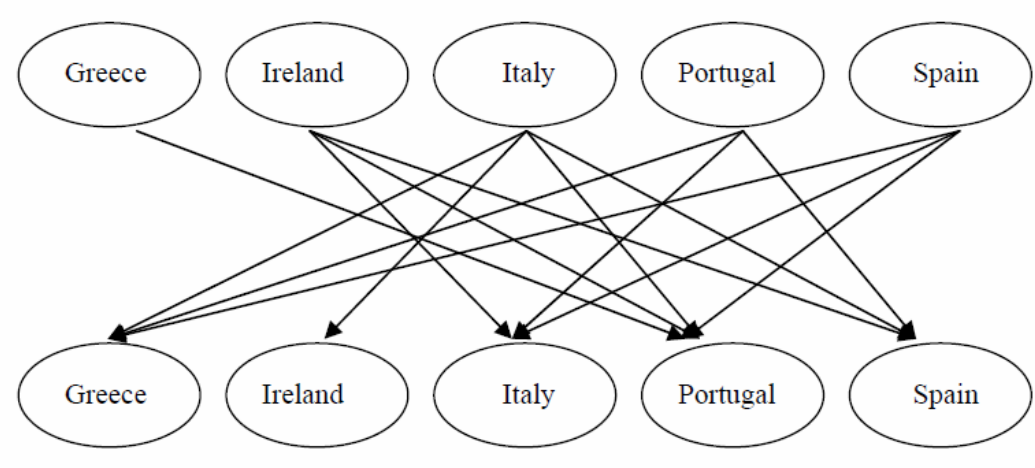

Crisis Period

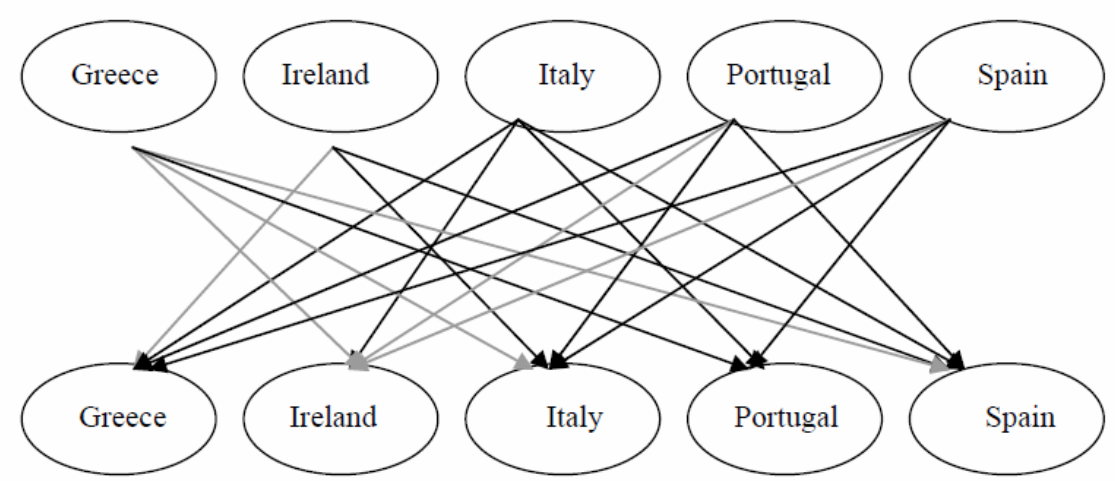


Figure 4: Causal relationships from EMU Central countries.

Figure 4a: Causal relationships from EMU Central to Peripheral countries Pre-crisis Period

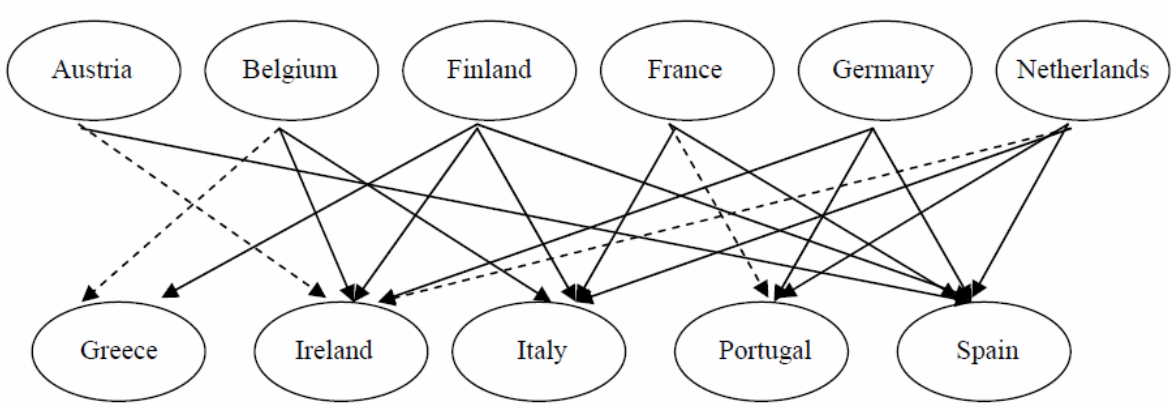

Crisis Period

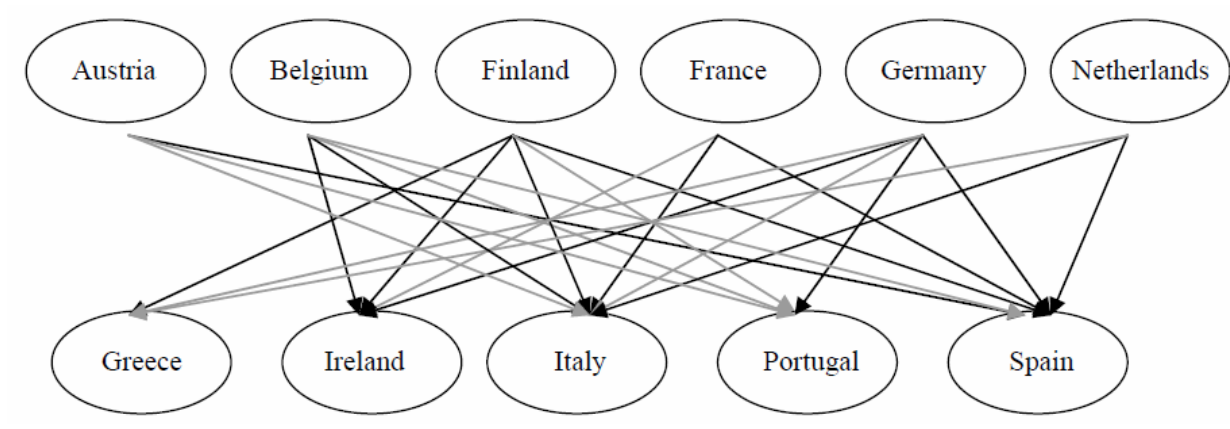

Figure4b: Causal relationships within EMU Central countries Pre-crisis Period

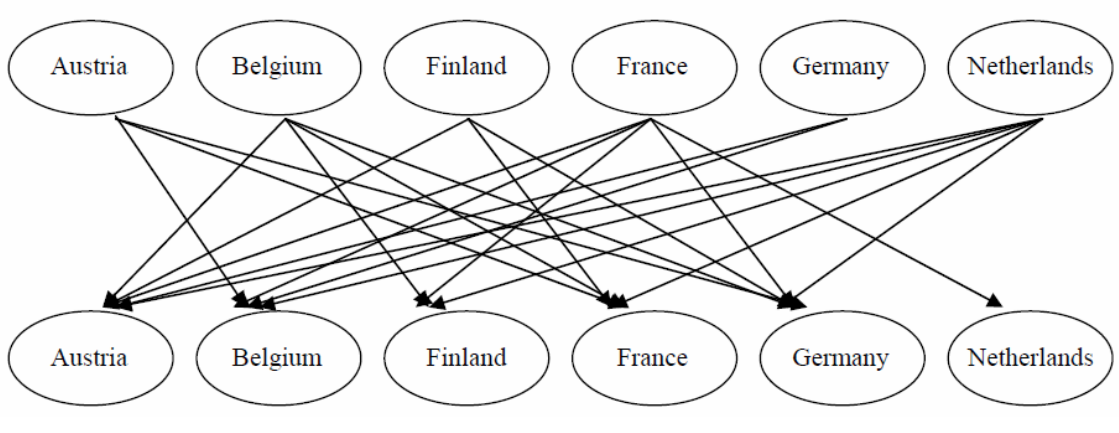

Crisis Period

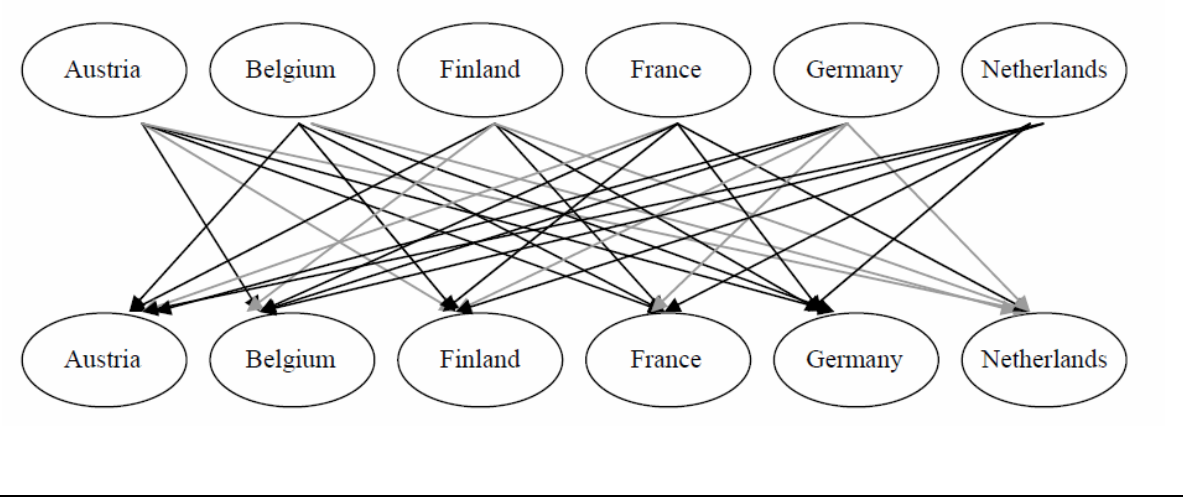


Table 1: Causal relationships' break dates ${ }^{\mathrm{a}}$

\begin{tabular}{|c|c|c|c|}
\hline Causal relationship & Break date & Causal relationship & Break date \\
\hline \multicolumn{2}{|c|}{$\begin{array}{l}\text { Panel A: 07/03/2008: ECB increases interest rates by } 25 \\
\text { basis points }\end{array}$} & \multicolumn{2}{|c|}{$\begin{array}{l}\text { Panel B: 09/15/2008: Lehman Brothers files for } \\
\text { bankruptcy }\end{array}$} \\
\hline $\mathrm{PT} \rightarrow \mathrm{NL}$ & $07 / 04 / 2008$ & $\mathrm{PT} \rightarrow \mathrm{IT}$ & $09 / 15 / 2008$ \\
\hline $\mathrm{SP} \rightarrow \mathrm{NL}$ & $07 / 04 / 2008$ & PT $\rightarrow$ GE & $10 / 08 / 2008$ \\
\hline FR $\rightarrow$ NL & $07 / 04 / 2008$ & $\mathrm{SP} \rightarrow \mathrm{GE}$ & $10 / 08 / 2008$ \\
\hline GE $\rightarrow$ FI & $07 / 04 / 2008$ & FR $\rightarrow$ FI & $10 / 08 / 2008$ \\
\hline $\mathbf{G E} \rightarrow \mathbf{N L}$ & $07 / 04 / 2008$ & $\mathrm{SP} \rightarrow \mathrm{IT}$ & $10 / 08 / 2008$ \\
\hline $\mathbf{N L} \rightarrow$ GE & $07 / 04 / 2008$ & $\mathrm{NL} \rightarrow$ FI & $10 / 28 / 2008$ \\
\hline $\mathrm{IE} \rightarrow \mathrm{NL}$ & $07 / 04 / 2008$ & $\mathrm{BE} \rightarrow \mathrm{GE}$ & $11 / 04 / 2008$ \\
\hline IT $\rightarrow$ GE & $07 / 04 / 2008$ & $\mathrm{IE} \rightarrow \mathrm{IT}$ & $11 / 14 / 2008$ \\
\hline GR $\rightarrow$ GE & $07 / 04 / 2008$ & GR $\rightarrow$ IT & $11 / 28 / 2008$ \\
\hline GR $\rightarrow$ NL & $07 / 04 / 2008$ & & \\
\hline FR $\rightarrow$ PT & $07 / 04 / 2008$ & & \\
\hline $\mathbf{F R} \rightarrow \mathrm{SP}$ & $07 / 04 / 2008$ & & \\
\hline $\mathrm{IE} \rightarrow \mathrm{GE}$ & $07 / 04 / 2008$ & & \\
\hline $\mathrm{BE} \rightarrow \mathrm{NL}$ & $07 / 24 / 2008$ & & \\
\hline \multicolumn{2}{|c|}{$\begin{array}{l}\text { Panel C: November 2009: Papandreou's government } \\
\text { reveals that its finances were far worse than previous } \\
\text { announcements }\end{array}$} & \multicolumn{2}{|c|}{ Panel D: 04/23/2010: Greece seeks financial support } \\
\hline $\mathrm{BE} \rightarrow \mathrm{PT}$ & $11 / 30 / 2009$ & $\mathrm{IT} \rightarrow \mathrm{AT}$ & $05 / 05 / 2010$ \\
\hline IT $\rightarrow$ PT & $12 / 03 / 2009$ & FR $\rightarrow$ IT & $05 / 07 / 2010$ \\
\hline $\mathrm{IT} \rightarrow \mathrm{SP}$ & $12 / 03 / 2009$ & GE $\rightarrow$ IT & $05 / 10 / 2010$ \\
\hline GR $\rightarrow$ AT & $12 / 21 / 2009$ & $\mathrm{GR} \rightarrow \mathrm{SP}$ & $05 / 10 / 2010$ \\
\hline PT $\rightarrow$ FR & $12 / 21 / 2009$ & $\mathrm{NL} \rightarrow \mathrm{IT}$ & $05 / 10 / 2010$ \\
\hline $\mathrm{SP} \rightarrow \mathrm{FR}$ & $12 / 21 / 2009$ & $\mathrm{IT} \rightarrow \mathrm{NL}$ & $05 / 10 / 2010$ \\
\hline \multicolumn{2}{|c|}{ Panel E: 11/21/2010: Ireland seeks financial support } & $\mathrm{SP} \rightarrow \mathrm{AT}$ & $05 / 10 / 2010$ \\
\hline FI $\rightarrow$ PT & $11 / 21 / 2010$ & $\mathbf{F R} \rightarrow \mathbf{A T}$ & $05 / 10 / 2010$ \\
\hline $\mathrm{FI} \rightarrow \mathrm{SP}$ & $11 / 21 / 2010$ & FR $\rightarrow$ BE & $05 / 11 / 2010$ \\
\hline $\mathrm{BE} \rightarrow \mathrm{SP}$ & $11 / 21 / 2010$ & FI $\rightarrow$ IT & $05 / 11 / 2010$ \\
\hline $\mathrm{FI} \rightarrow \mathrm{IE}$ & $11 / 21 / 2010$ & FI $\rightarrow$ GR & $05 / 11 / 2010$ \\
\hline $\mathrm{BE} \rightarrow \mathrm{IE}$ & $11 / 21 / 2010$ & AT $\rightarrow$ GR & $05 / 11 / 2010$ \\
\hline $\mathrm{NL} \rightarrow \mathrm{IE}$ & $11 / 21 / 2010$ & $\mathbf{A T} \rightarrow$ PT & $05 / 11 / 2010$ \\
\hline $\mathbf{A T} \rightarrow \mathrm{BE}$ & $11 / 21 / 2010$ & $\mathrm{BE} \rightarrow \mathrm{IT}$ & $05 / 11 / 2010$ \\
\hline $\mathbf{A T} \rightarrow \mathbf{N L}$ & $11 / 21 / 2010$ & $\mathrm{BE} \rightarrow \mathrm{GR}$ & $05 / 11 / 2010$ \\
\hline $\mathrm{BE} \rightarrow \mathrm{FR}$ & $11 / 21 / 2010$ & $\mathrm{IE} \rightarrow \mathrm{BE}$ & $05 / 11 / 2010$ \\
\hline FI $\rightarrow$ FR & $11 / 21 / 2010$ & IE $\rightarrow$ GR & $05 / 12 / 2010$ \\
\hline IT $\rightarrow$ IE & $11 / 21 / 2010$ & IT $\rightarrow$ GR & $05 / 12 / 2010$ \\
\hline $\mathrm{PT} \rightarrow \mathrm{IE}$ & $11 / 21 / 2010$ & $\mathrm{SP} \rightarrow \mathrm{GR}$ & $05 / 12 / 2010$ \\
\hline $\mathrm{SP} \rightarrow \mathrm{IE}$ & $11 / 21 / 2010$ & & \\
\hline $\mathrm{SP} \rightarrow \mathrm{PT}$ & $11 / 21 / 2010$ & & \\
\hline $\mathrm{GE} \rightarrow \mathrm{IE}$ & $11 / 22 / 2010$ & & \\
\hline $\mathbf{A T} \rightarrow \mathrm{SP}$ & $11 / 23 / 2010$ & & \\
\hline $\mathrm{AT} \rightarrow \mathrm{IT}$ & $11 / 23 / 2010$ & & \\
\hline $\mathbf{G E} \rightarrow \mathbf{B E}$ & $11 / 24 / 2010$ & & \\
\hline $\mathrm{NL} \rightarrow \mathrm{BE}$ & $11 / 24 / 2010$ & & \\
\hline $\mathbf{N L} \rightarrow$ FR & $11 / 24 / 2010$ & & \\
\hline FI $\rightarrow$ BE & $11 / 24 / 2010$ & & \\
\hline $\mathrm{SP} \rightarrow \mathrm{BE}$ & $11 / 24 / 2010$ & & \\
\hline $\mathbf{G R} \rightarrow \mathbf{B E}$ & $11 / 24 / 2010$ & & \\
\hline $\mathrm{IT} \rightarrow \mathrm{BE}$ & $11 / 24 / 2010$ & & \\
\hline $\mathrm{PT} \rightarrow \mathrm{BE}$ & $11 / 24 / 2010$ & & \\
\hline $\mathbf{A T} \rightarrow$ FI & $11 / 25 / 2010$ & & \\
\hline $\mathrm{NL} \rightarrow \mathrm{SP}$ & $11 / 25 / 2010$ & & \\
\hline GE $\rightarrow$ GR & $12 / 10 / 2010$ & & \\
\hline $\mathbf{N L} \rightarrow$ GR & $12 / 10 / 2010$ & & \\
\hline
\end{tabular}

a Notes: Five triggering events explain $70 \%$ of total break dates.

AT, BE, FI, FR, GE, GR, IE, IT, NL, PT, and SP stand for Austria, Belgium, Finland, France, Germany, Greece, Ireland, Italy, the Netherlands, Portugal and Spain, respectively. 
Table 2: Causality running from EMU Peripheral countries ${ }^{b}$

Panel A: Causality running from EMU Peripheral to Central countries

\begin{tabular}{|c|c|c|c|c|}
\hline & $\begin{array}{c}\text { Pre-crisis } \\
\text { period }\end{array}$ & Crisis period & Break date & $\begin{array}{l}\text { Causality } \\
\text { Changes }\end{array}$ \\
\hline $\mathrm{IE} \rightarrow \mathrm{AT}$ & No & Yes & $09 / 18 / 2009$ & New \\
\hline $\mathrm{IE} \rightarrow \mathrm{BE}$ & No & Yes & $05 / 11 / 2010$ & New \\
\hline IE $\rightarrow$ FI & Yes & Yes & $01 / 29 / 2009$ & Intensification \\
\hline $\mathrm{IE} \rightarrow$ FR & No & Yes & $03 / 23 / 2010$ & New \\
\hline $\mathrm{IE} \rightarrow \mathrm{GE}$ & Yes & Yes & $07 / 04 / 2008$ & Reduction \\
\hline $\mathrm{IE} \rightarrow \mathrm{NL}$ & No & Yes & $07 / 04 / 2008$ & New \\
\hline $\mathrm{IT} \rightarrow \mathrm{AT}$ & Yes & Yes & $05 / 05 / 2010$ & Reduction \\
\hline $\mathrm{IT} \rightarrow \mathrm{BE}$ & Yes & Yes & $11 / 24 / 2010$ & Intensification \\
\hline IT $\rightarrow$ FI & Yes & Yes & $07 / 04 / 2010$ & Intensification \\
\hline IT $\rightarrow$ FR & No & Yes & $01 / 05 / 2009$ & New \\
\hline $\mathrm{IT} \rightarrow \mathrm{GE}$ & Yes & Yes & $07 / 04 / 2008$ & Reduction \\
\hline $\mathrm{IT} \rightarrow \mathrm{NL}$ & No & No & $05 / 10 / 2010$ & - \\
\hline $\mathbf{G R} \rightarrow \mathbf{A T}$ & No & Yes & $12 / 21 / 2009$ & New \\
\hline $\mathrm{GR} \rightarrow \mathrm{BE}$ & No & Yes & $11 / 24 / 2010$ & New \\
\hline $\mathbf{G R} \rightarrow$ FI & No & Yes & $07 / 04 / 2010$ & New \\
\hline GR $\rightarrow$ FR & No & Yes & $01 / 06 / 2009$ & New \\
\hline GR $\rightarrow$ GE & No & No & $07 / 04 / 2008$ & - \\
\hline $\mathbf{G R} \rightarrow \mathbf{N L}$ & No & No & $07 / 04 / 2008$ & - \\
\hline $\mathbf{P T} \rightarrow \mathbf{A T}$ & No & Yes & $01 / 06 / 2009$ & New \\
\hline PT $\rightarrow$ BE & Yes & Yes & $11 / 24 / 2010$ & Intensification \\
\hline PT $\rightarrow$ FI & Yes & Yes & $07 / 04 / 2010$ & Reduction \\
\hline PT $\rightarrow$ FR & No & Yes & $12 / 21 / 2009$ & New \\
\hline PT $\rightarrow$ GE & No & Yes & $10 / 08 / 2008$ & New \\
\hline PT $\rightarrow$ NL & No & Yes & $07 / 04 / 2008$ & New \\
\hline $\mathrm{SP} \rightarrow \mathrm{AT}$ & Yes & Yes & $05 / 10 / 2010$ & Intensification \\
\hline $\mathrm{SP} \rightarrow \mathrm{BE}$ & No & Yes & $11 / 24 / 2010$ & New \\
\hline $\mathrm{SP} \rightarrow$ FI & No & Yes & $07 / 04 / 2010$ & New \\
\hline $\mathrm{SP} \rightarrow$ FR & Yes & Yes & $12 / 21 / 2009$ & Intensification \\
\hline $\mathrm{SP} \rightarrow \mathrm{GE}$ & No & Yes & $10 / 08 / 2008$ & New \\
\hline $\mathrm{SP} \rightarrow \mathrm{NL}$ & No & Yes & $07 / 04 / 2008$ & New \\
\hline
\end{tabular}

Panel B: Causality running within EMU Peripheral countries

\begin{tabular}{|c|c|c|c|c|}
\hline & $\begin{array}{l}\text { Pre-crisis } \\
\text { period }\end{array}$ & Crisis period & Break date & $\begin{array}{c}\text { Causality } \\
\text { changes }\end{array}$ \\
\hline $\mathrm{IE} \rightarrow \mathrm{IT}$ & Yes & Yes & $11 / 14 / 2008$ & Intensification \\
\hline IE $\rightarrow$ GR & No & Yes & $05 / 12 / 2010$ & New \\
\hline $\mathrm{IE} \rightarrow$ PT & Yes & Yes & $06 / 22 / 2009$ & Intensification \\
\hline $\mathrm{IE} \rightarrow \mathrm{SP}$ & Yes & Yes & $03 / 02 / 2009$ & Intensification \\
\hline $\mathrm{IT} \rightarrow \mathrm{IE}$ & Yes & Yes & $11 / 21 / 2010$ & Intensification \\
\hline IT $\rightarrow$ GR & Yes & Yes & $05 / 12 / 2010$ & Intensification \\
\hline IT $\rightarrow$ PT & Yes & Yes & $12 / 03 / 2009$ & Reduction \\
\hline $\mathrm{IT} \rightarrow \mathrm{SP}$ & Yes & Yes & $12 / 03 / 2009$ & Intensification \\
\hline $\mathrm{GR} \rightarrow \mathrm{IE}$ & No & Yes & $07 / 05 / 2010$ & New \\
\hline GR $\rightarrow$ IT & No & Yes & $11 / 28 / 2008$ & New \\
\hline $\mathbf{G R} \rightarrow \mathbf{P T}$ & Yes & Yes & $02 / 02 / 2010$ & Intensification \\
\hline $\mathrm{GR} \rightarrow \mathrm{SP}$ & No & Yes & $05 / 10 / 2010$ & New \\
\hline PT $\rightarrow$ IE & No & Yes & $11 / 21 / 2010$ & New \\
\hline $\mathrm{PT} \rightarrow \mathrm{IT}$ & Yes & Yes & $09 / 15 / 2008$ & Reduction \\
\hline PT $\rightarrow$ GR & Yes & Yes & $08 / 05 / 2010$ & Intensification \\
\hline $\mathrm{PT} \rightarrow \mathrm{SP}$ & Yes & Yes & $15 / 01 / 2010$ & Intensification \\
\hline $\mathrm{SP} \rightarrow \mathrm{IE}$ & No & Yes & $11 / 21 / 2010$ & New \\
\hline $\mathrm{SP} \rightarrow \mathrm{IT}$ & Yes & Yes & $10 / 08 / 2008$ & Intensification \\
\hline $\mathrm{SP} \rightarrow \mathrm{GR}$ & Yes & Yes & $05 / 12 / 2010$ & Intensification \\
\hline $\mathrm{SP} \rightarrow \mathrm{PT}$ & Yes & Yes & $11 / 21 / 2010$ & Intensification \\
\hline
\end{tabular}

b Notes: AT, BE, FI, FR, GE, GR, IE, IT, NL, PT, and SP stand for Austria, Belgium, Finland, France, Germany, Greece, Ireland, Italy, the Netherlands, Portugal and Spain, respectively. Bold values indicate absence of Granger-causality. 
Table 3: Causality running from EMU Central countries ${ }^{c}$

Panel A: Causality running from EMU Central to Peripheral countries

\begin{tabular}{|c|c|c|c|c|}
\hline & $\begin{array}{c}\text { Pre-crisis } \\
\text { period }\end{array}$ & Crisis period & Break date & $\begin{array}{c}\text { Causality } \\
\text { changes }\end{array}$ \\
\hline $\mathrm{AT} \rightarrow \mathrm{IE}$ & Yes & No & $07 / 05 / 2010$ & - \\
\hline $\mathrm{AT} \rightarrow \mathrm{IT}$ & No & Yes & $11 / 23 / 2010$ & New \\
\hline AT $\rightarrow$ GR & No & No & $05 / 11 / 2010$ & - \\
\hline $\mathbf{A T} \rightarrow$ PT & No & Yes & $05 / 11 / 2010$ & New \\
\hline $\mathbf{A T} \rightarrow \mathrm{SP}$ & Yes & Yes & $11 / 23 / 2010$ & Intensification \\
\hline $\mathrm{BE} \rightarrow \mathrm{IE}$ & Yes & Yes & $11 / 21 / 2010$ & Intensification \\
\hline $\mathrm{BE} \rightarrow \mathrm{IT}$ & Yes & Yes & $05 / 11 / 2010$ & Intensification \\
\hline $\mathrm{BE} \rightarrow \mathrm{GR}$ & Yes & No & $05 / 11 / 2010$ & - \\
\hline $\mathrm{BE} \rightarrow \mathrm{PT}$ & No & Yes & $11 / 30 / 2009$ & New \\
\hline $\mathrm{BE} \rightarrow \mathrm{SP}$ & No & Yes & $11 / 21 / 2010$ & New \\
\hline FI $\rightarrow$ IE & Yes & Yes & $11 / 21 / 2010$ & Intensification \\
\hline FI $\rightarrow$ IT & Yes & Yes & $05 / 11 / 2010$ & Intensification \\
\hline FI $\rightarrow$ GR & Yes & Yes & $05 / 11 / 2010$ & Intensification \\
\hline FI $\rightarrow$ PT & No & Yes & $11 / 21 / 2010$ & New \\
\hline $\mathrm{FI} \rightarrow \mathrm{SP}$ & Yes & Yes & $11 / 21 / 2010$ & Intensification \\
\hline FR $\rightarrow$ IE & No & Yes & $07 / 05 / 2010$ & New \\
\hline FR $\rightarrow$ IT & Yes & Yes & $05 / 07 / 2010$ & Intensification \\
\hline FR $\rightarrow$ GR & No & No & $05 / 03 / 2010$ & - \\
\hline FR $\rightarrow$ PT & Yes & No & $07 / 04 / 2008$ & - \\
\hline $\mathbf{F R} \rightarrow \mathrm{SP}$ & Yes & Yes & $07 / 04 / 2008$ & Intensification \\
\hline $\mathrm{GE} \rightarrow \mathrm{IE}$ & Yes & Yes & $11 / 22 / 2010$ & Reduction \\
\hline $\mathrm{GE} \rightarrow \mathrm{IT}$ & No & Yes & $05 / 10 / 2010$ & New \\
\hline GE $\rightarrow$ GR & No & Yes & $12 / 10 / 2010$ & New \\
\hline GE $\rightarrow$ PT & Yes & Yes & $01 / 08 / 2008$ & Reduction \\
\hline $\mathrm{GE} \rightarrow \mathrm{SP}$ & Yes & Yes & $01 / 14 / 2010$ & Intensification \\
\hline $\mathrm{NL} \rightarrow \mathrm{IE}$ & Yes & No & $11 / 21 / 2010$ & - \\
\hline $\mathrm{NL} \rightarrow \mathrm{IT}$ & Yes & Yes & $05 / 10 / 2010$ & Reduction \\
\hline NL $\rightarrow$ GR & No & Yes & $12 / 10 / 2010$ & New \\
\hline NL $\rightarrow$ PT & Yes & Yes & $08 / 18 / 2008$ & Reduction \\
\hline $\mathrm{NL} \rightarrow \mathrm{SP}$ & Yes & Yes & $11 / 25 / 2010$ & Reduction \\
\hline
\end{tabular}

Panel B: Causality running within EMU Central countries

\begin{tabular}{|c|c|c|c|c|}
\hline & $\begin{array}{c}\text { Pre-crisis } \\
\text { period }\end{array}$ & Crisis period & Break date & $\begin{array}{c}\text { Causality } \\
\text { changes }\end{array}$ \\
\hline $\mathrm{AT} \rightarrow \mathrm{BE}$ & Yes & Yes & $11 / 21 / 2010$ & Intensification \\
\hline $\mathrm{AT} \rightarrow \mathrm{FI}$ & No & Yes & $11 / 25 / 2010$ & New \\
\hline $\mathrm{AT} \rightarrow \mathrm{FR}$ & Yes & Yes & $06 / 10 / 2008$ & Intensification \\
\hline $\mathrm{AT} \rightarrow \mathrm{GE}$ & Yes & Yes & $07 / 01 / 2008$ & Intensification \\
\hline $\mathrm{AT} \rightarrow \mathrm{NL}$ & No & Yes & $11 / 21 / 2010$ & New \\
\hline $\mathrm{BE} \rightarrow \mathrm{AT}$ & Yes & Yes & $06 / 01 / 2009$ & Reduction \\
\hline $\mathrm{BE} \rightarrow \mathrm{FI}$ & Yes & Yes & $06 / 04 / 2010$ & Intensification \\
\hline $\mathrm{BE} \rightarrow \mathrm{FR}$ & Yes & Yes & $11 / 21 / 2010$ & Intensification \\
\hline $\mathrm{BE} \rightarrow \mathrm{GE}$ & Yes & Yes & $11 / 04 / 2008$ & Reduction \\
\hline $\mathrm{BE} \rightarrow \mathrm{NL}$ & No & Yes & $07 / 24 / 2008$ & New \\
\hline FI $\rightarrow$ AT & Yes & Yes & $05 / 01 / 2009$ & Intensification \\
\hline $\mathrm{FI} \rightarrow \mathrm{BE}$ & No & Yes & $11 / 24 / 2010$ & New \\
\hline FI $\rightarrow$ FR & Yes & Yes & $11 / 21 / 2010$ & Intensification \\
\hline $\mathrm{FI} \rightarrow \mathrm{GE}$ & Yes & Yes & $07 / 01 / 2008$ & Intensification \\
\hline FI $\rightarrow$ NL & No & Yes & $06 / 04 / 2010$ & New \\
\hline FR $\rightarrow$ AT & No & Yes & $05 / 10 / 2010$ & New \\
\hline $\mathrm{FR} \rightarrow \mathrm{BE}$ & Yes & Yes & $05 / 11 / 2010$ & Reduction \\
\hline FR $\rightarrow$ FI & Yes & Yes & $10 / 08 / 2008$ & Reduction \\
\hline FR $\rightarrow$ GE & Yes & Yes & $07 / 01 / 2008$ & Intensification \\
\hline FR $\rightarrow$ NL & Yes & Yes & $07 / 04 / 2008$ & Intensification \\
\hline GE $\rightarrow$ AT & Yes & Yes & $06 / 06 / 2009$ & Intensification \\
\hline $\mathrm{GE} \rightarrow \mathrm{BE}$ & Yes & Yes & $11 / 24 / 2010$ & Intensification \\
\hline $\mathrm{GE} \rightarrow \mathrm{FI}$ & No & Yes & $07 / 04 / 2008$ & New \\
\hline GE $\rightarrow$ FR & No & Yes & $02 / 19 / 2008$ & New \\
\hline $\mathrm{GE} \rightarrow \mathrm{NL}$ & No & Yes & $07 / 04 / 2008$ & New \\
\hline $\mathrm{NL} \rightarrow \mathrm{AT}$ & Yes & Yes & $01 / 06 / 2009$ & Intensification \\
\hline $\mathrm{NL} \rightarrow \mathrm{BE}$ & Yes & Yes & $11 / 24 / 2010$ & Intensification \\
\hline NL $\rightarrow$ FI & Yes & Yes & $10 / 28 / 2008$ & Reduction \\
\hline $\mathrm{NL} \rightarrow \mathrm{FR}$ & Yes & Yes & $11 / 24 / 2010$ & Reduction \\
\hline $\mathrm{NL} \rightarrow \mathrm{GE}$ & Yes & Yes & $07 / 04 / 2008$ & Intensification \\
\hline
\end{tabular}

c Notes: AT, BE, FI, FR, GE, GR, IE, IT, NL, PT, and SP stand for Austria, Belgium, Finland, France, Germany, Greece, Ireland, Italy, the Netherlands, Portugal and Spain, respectively.

Bold values indicate absence of Granger-causality. 